\title{
Adaptation Mechanisms of Camels (Camelus dromedarius) for Desert Environment: A Review
}

Mulu Gebreselassie Gebreyohanes and Awol Mohammed Assen*

Wollo University, Dessie, Ethiopia

*Corresponding author: Awol Mohammed Assen, Wollo University, Dessie, Ethiopia, Tel: 033-311-5204; E-mail: awolm8@gmail.com

Rec date: September 20, 2017; Acc date: November 03, 2017; Pub date: November 06, 2017

Copyright: (c) 2017 Gebreyohanes GM, et al. This is an open-access article distributed under the terms of the Creative Commons Attribution License, which permits unrestricted use, distribution, and reproduction in any medium, provided the original author and source are credited.

\begin{abstract}
Dromedary camels have a number of adaptation mechanisms that help them to survive successfully in dry and arid climates in which there is shortage of water and high environmental temperature. For survival in desert environment, camels have physiological, anatomical and behavioral adaptation mechanisms. Water conservation ability, the unique features of blood, thermoregulation, and efficient digestion and metabolism are among the physiological adaptations. Anatomically the nature of skin coat, eye, nostril and lips, large body size and long height and large foot pads contribute for their survival. Moreover the feeding, drinking, thermal and sexual behavior of camels also plays a major role in succeeding their existence in the desert environment. Despite of their great contribution for the livelihood of many pastoralists in different parts of the world in which other animals face difficulties, camels are the most neglected domestic animals by the scientific community. Therefore the value camels should have to get emphasis and awareness should have to be created to the community about health care and management of camels to improve their production and productivity.
\end{abstract}

Keywords: Adaptation; Camel; Desert; dromedarius

\section{Introduction}

Dromedary camel (Camelus dromedarius) is an important livestock species uniquely adapted to hot arid environments. It is most numerous in the arid areas of Africa, particularly in the arid lowlands of Eastern Africa namely, Somalia, Sudan, Ethiopia, Kenya and Djibouti. Camels have been bred owing to the extra ordinary power to withstand thirst and hunger for long duration in the most inhospitable ecological conditions [1]. The ability of the camel to survive in harsh areas of the world, its endurance in prolonged drought, and above all its high potential to convert the scanty resources of the desert into milk and meat makes them more important to the pastoralists [2].

The camel (Camelus dromedarius) has adapted mechanisms that allow it to withstand prolonged water deprivation, high heat load especially in the absence of readily available water and survive when feed resources are scarce or of poor quality [3]. They are well suited to the harsh desert environments which are characterized by seasonal shortage of water and vegetation as well as high ambient temperatures and other environmental stresses. This is because the camel is anatomically and physiologically equipped with adaptive homeostatic mechanisms [4] enabling it to survive, produce and reproduce, and to support human life in such arid zones [5]. Due to this camels are good source of meat and milk especially in areas where the climate adversely affects the performance of other animals [6].

Camels (Camelus dromedarius) play a significant role as a primary source of subsistence in the lowlands. Camels have diverse roles in livelihood of the pastoralists, including the building of assets, insurance against unexpected events, transportation of goods, food supply and income generation. Very recently camels also start to play pronounced role in the export revenue of the countries in both live animal and carcass export [7]. Camels live in wide arid and semiarid areas, which are not suitable for crop production and less suitable for other livestock production. Therefore, in these areas camel is superior to all other livestock in terms of food security. With continuing land degradation and rapidly growing human population, the camel's importance is increasing [8]. Therefore this paper reviews the different adaptation mechanism of dromedary camels for desert environment.

\section{Adaptations of Camels to the Desert Environment}

\section{Physiological adaptations}

Water conservation: Desert adapted camels have evolved physiological adaptations that reduce the amount of water lost or are able to tolerate significant amounts of water loss [9]. Where green forage is available in mild climates, the camel may go several months without drinking. During the winter and cold seasons of the year camels can go without water for months. They do not even drink when offered water. Under very hot conditions, it may drink only every eight to ten days and lose up to 30 percent of its body weight through dehydration [10]. When the mean temperature reach $30-35^{\circ} \mathrm{C}$, camels can go 10-15 days without water but when the temperature exceeds $40^{\circ} \mathrm{C}$, shorter periods between watering is necessary [11]

The digestive and urinary tracts are well specialized in water conservation. Cattle lose 20 to 40 liters of fluid daily through feces, whereas camels lose only 1.3 liters. This is one of the primary methods for resisting water deprivation in the desert. Fluid is absorbed in the end part of the intestines, where the small fecal balls are produced [12].

The rumen helps maintain water balance in two ways. First, the rumen of hydrated ungulates and the foregut of camels contain a large volume of water, approximately equal to $20 \%$ of body weight, and may buffer ungulates against short term water deprivation. During the first few days of dehydration, fluid contained in the rumen is used to maintain water balance of blood and body tissues and represents a large portion (50-70\%) of the water lost during dehydration. Second, 
after dehydration in some species, the rumen plays a role in the prevention of haemolysis and osmotic tissue shock during rapid rehydration [13].

The kidney is an important organ involved in the removal of unwanted nitrogenous substances, excess water and relative maintenance of osmotic concentration of the blood [14]. The camel's kidneys play a major role in the process of conserving water through increasing the osmolarity of urine. The kidney is characterized by a long loop of henle, and a well-developed medulla (the ratio medulla: cortex is about 4:1) [5]. During dehydration, the kidneys reduce water losses both by decreasing the glomerular filtration rate and by increasing the tubular re-absorption of water [15].

The long loops of henle, which are four to six times longer than in cattle, have the function of both concentrating urine and reducing its flow. A dehydrated camel urinates only drops of concentrated urine being shown by white stripes of salt crystals on the hind legs and tail. This concentrated urine not only serves to conserve water, but also allows camels to drink water which is more concentrated than sea water (above $3 \% \mathrm{NaCl}$ ), and to eat salty plants (halophytes) that would otherwise be toxic. Anti-diuretic hormone $(\mathrm{ADH})$ is important in regulating the volume of urine excreted and its concentration. $\mathrm{ADH}$ is produced in the hypothalamus and is released into the blood stream in response to increased blood osmolarity [16]. Larger release of $\mathrm{ADH}$ leads to a fast renal response that causes increased re-absorption of water. This leads to a smaller volume of more concentrated urine being excreted [17].

The body of camels can tolerate loss of water over $30 \%$ of body weight whereas most mammals die if they lose half of this value [18]. Rehydration following a period of water deprivation is important for animal survival. A camel may drink more than one third of its body weight as it rehydrates. In terms of actual water intake [19] reported 110 liters in 10 minutes. In other animals rehydration at these levels would lead to over hydration and possibly death. The camel is able to do this as large amounts of water can be stored for up to 24 hours in the gut to avoid a rapid dilution of the blood [20].

\begin{tabular}{|l|l|l|}
\hline Species & $\begin{array}{l}\text { Water turn over } \\
\text { ml/Kg/day }\end{array}$ & \%Corpora water \\
\hline Dromedary Camel & $38-76$ & 72 \\
\hline Sheep & $62-127$ & 60 \\
\hline Goat & $76-196$ & 65 \\
\hline Zebu & $63-178$ & 65 \\
\hline Buffalo & $108-203$ & 66 \\
\hline
\end{tabular}

Table 1: Water turnover in a dromedary and other ruminants.

\section{Unique features of blood}

The camel can dehydrate without compromising blood viscosity. The camel's blood plays a principal role in adaptive mechanisms to high heat load and dehydration [5]. Blood composition and volume remains relatively constant and haemoglobin function remains normal [20].

The erythrocytes of the camel are oval shaped and non-nucleated which resist osmotic variation without rupturing; these cells can swell to twice their initial volume following rehydration $[5,19]$. The oval red blood cells in dromedary camels can easily flow quicker in a dehydrated state of the animal as compared to the round shaped red blood cells in other mammals. These red blood cells are also enormously expansible [21]. Because of the shorter and less saturated fatty acid chains that they identified, the dromedary red cell membranes are more fluid than those of human red cells and perhaps this explains the remarkable stretching ability in camels. The ellipsoid shape of camel erythrocytes is very stable and that the cytoskeleton differs from that of human red cells and they may expand with distilled water to $400 \%$ before they rupture [22].

Another unique feature of the erythrocytes is their long life span when the camel is dehydrated. The life span of the erythrocytes of hydrated camels is 90 to 120 days. When camels are chronically dehydrated during summer $\left(40^{\circ} \mathrm{C}\right.$ mean during day; $20^{\circ} \mathrm{C}$ mean at night) the life span of erythrocytes extends to 150 days. Erythrocyte turnover is water and energy expensive. Therefore extending the life span of erythrocytes reduces energy and water expenditure [5].

\section{Thermoregulation}

Body temperature regulation: A fully hydrated camel has a diurnal body temperature range of 36 to $38^{\circ} \mathrm{C}$. However when dehydrated and exposed to high environmental heat load body temperature may fluctuate by 6 to $7^{\circ} \mathrm{C}$, from approximately 34 to $41^{\circ} \mathrm{C}$ [3]. Other animals also allow body temperature to increase but not to the same extent. For example Bos Taurus cattle will have a 2 to $4^{\circ} \mathrm{C}$ variation in body temperature when exposed to hot conditions [23]. The increase in body temperature of camels exposed to high heat load, especially following a $2{ }^{\circ} \mathrm{C}$ reduction below the normal minimum, is advantageous because it allows a considerable amount of heat to be stored during the day and dissipated at night (by radiation) without the expenditure of water [24]

Selective brain cooling: Selective brain cooling has been postulated as a mechanism for animals to maintain brain temperature below thermal critical values when body temperature increases. The carotid rete, an area of the carotid artery divided into a series of small blood vessels posterior to the brain, contacts a network of small veinules returning blood from the nasal passages. Heat is transferred from the warmer arterial blood to venous blood cooled by respiratory evaporation in the nasal passage. Blood entering the brain is $3.98^{\circ} \mathrm{C}$ cooler than core body temperatures. This observation has allowed researchers to conclude that selective brain cooling is an adaptation to protect the brain when core body temperature increases. By cooling the brain the animal is able to tolerate higher temperatures [13].

The camel has a bi-phasic air flow pattern, i.e. the inspiratory and expiratory flow rates through the nasal turbinates are similar. The biphasic breathing pattern also reduces water use [3]. Camels, like most other animals, need to maintain a constant brain temperature. However, this is very difficult considering they live in an extreme hot environment. To assist this, camels have a "rete mirabile", it is a complex of arteries and veins lying very close to each other which utilizes countercurrent blood flow to cool the blood flowing to the brain. Doing so helps camels to maintain a stable brain temperature, essential for survival [25]. Under normal conditions the cool venous blood, after having passed over the nasal cavity, travels via a general circulation. However, when temperature increases in the body the nasal and the angular veins ( 1 and 2) (figure 1) become wider while the facial vein (3) (figure 1) is constricted. When this situation occurs the cool venous blood can only go in one direction through the 
ophthalmic veins to the cavernous sinus which then cools the arterial blood through heat exchange in the carotid artery [5].

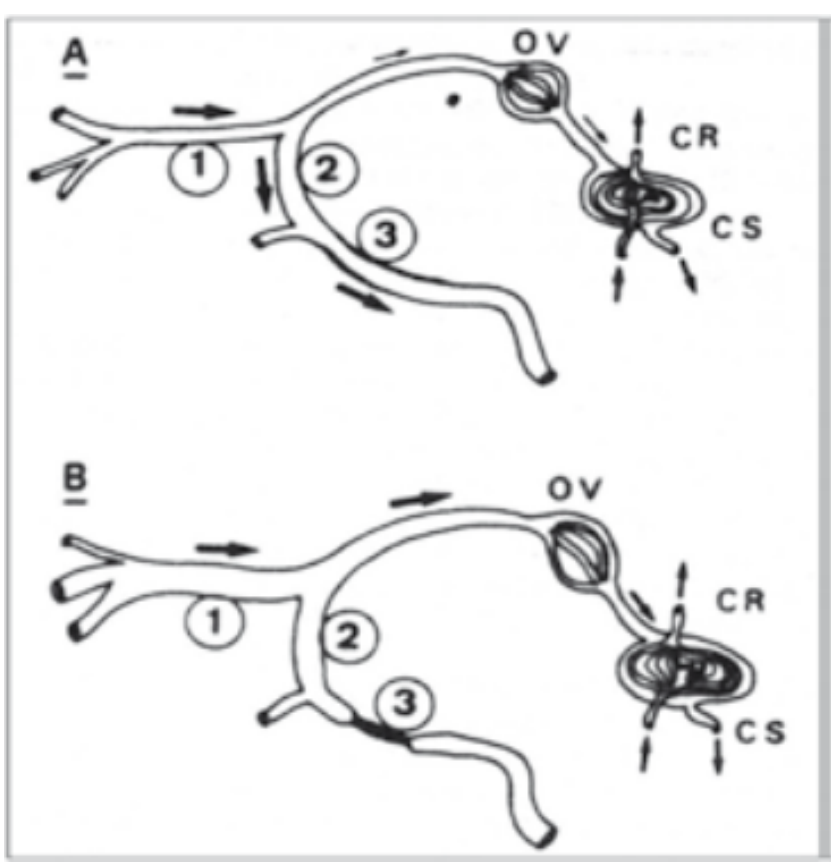

Figure 1: Superficial veins of the camel head under normal conditions (A) and hot conditions (B).

\section{Digestion and metabolism}

Gastric digestion: The pre-stomachs of the camel are characterized by the presence of only three compartments in comparison with true ruminants. The great digestive capacity of cellulose by camels is due to a specific and differentiated motility, a very active micro flora and better microbial digestion and more significant food mixing in prestomachs [5].

Lipid metabolism: The proverbial capacity of the dromedary to resist thirst and lack of food is related to remarkable adaptive mechanisms, including the mobilization of the body reserves of lipids (fatty tissue) during malnutrition and the storage of fat during favorable periods [26]. The cholesterol concentration increases in the dehydrated dromedary as a consequence of the hypothyroidism. In dehydrated dromedaries, liver lipids decrease from 13 to $2.5 \%$, indicating a strong mobilization of hepatic lipids. On the contrary, concentrations of triglycerides and free fatty acids remain unchanged. However; a severe water deprivation during 14 days would induce a lipolysis revealed by the increase in concentrations of triglycerides, free fatty acids, phospholipids and cholesterol [5].

Glycidic metabolism: After a 10 days water deprivation, the glycemia increases from 20 to $80 \%$ without glucosuria [27]. The glucose urinary elimination is accompanied by enormous water losses like in diabetes cases. Thus, a dehydrated camel reduces moisture losses by maintaining a high glycemia and a practically null glucosuria. The hypo-insulinemia would allow the camel to maintain a low basal metabolism by decreasing glucose use [5].
Nitrogen metabolism: The nitrogen recycling in Camelids increases in the case of lower proteins in diet and/or dehydration [28]. This great aptitude of urea recycling is due to very powerful mechanisms whose effectiveness does not deteriorate in the case of dehydration [29]. The dromedary has very particular anatomical structures in the kidney, which limit considerably the urea elimination by the urine. The urea appears to play a significant role during dehydration in the dromedary. Indeed, by its osmotic effects, the urea attracts the water of other mediums towards the plasma. The tubular re-absorption of urea would be under the hormonal influence of the anti-diuretic hormone (ADH). So the water re-absorption in the collecting tube is accompanied by that of the urea [5]. Camelids are, therefore, particularly well adapted to lower nitrogen diets by limiting the urinary rejection of urea. Hence urea supplementation in the diet can cause toxicity. The animal can also produce urine with extremely low concentration of urea, when fed a diet low in proteins. Thus the camel can conserve urea for protein synthesis when food is low in protein or when growing or pregnant [15].

\section{Anatomical adaptation of camels}

Skin and coat: The camels' thick coats insulate them from the intense heat radiated from desert sand and during the summer the coat becomes lighter in color, reflecting light as well as helping to avoid sunburn. Dromedaries have a pad of thick tissue over the sternum called the pedestal. When the animal lies down, the pedestal and other small areas of padded contact points raise the body from the hot surface and allow cooling air to pass under the body [22]. In addition, the camel's coat which is more hairy than wooly create a favorable buffer zone that separate body surface from the surrounding climatic conditions [30]. Coat thickness varies through growth and shedding to cope with prevailing environmental conditions during the different seasons of the year [31].

The sweat evaporates directly from the skin surface in the dromedary camel rather than from the tip of the hairs as it does on heavily furred animals. Latent heat of vaporization is therefore drawn directly from the skin. Evaporation that takes place directly on the skin saves more energy and cools the skin more effectively than if the evaporations took place at the tip of the hairs [15].

Eye, nostril and lips: The slit-like closable nostril protects against blowing sand and moistens air on its way to the lungs. When camel exhales, water vapor become trapped in their nostrils and is reabsorbed into the body to conserve water [32]. Split upper lip assists feed selection and easy prehension during browsing and their mouths have a thick leathery lining, allowing them to chew thorny desert plants. The small wound ears covered with tufts of hair is protected from entering of the blowing sand [33]. Camels have long eyelashes that help protect the eyes from the sun and the blowing sand [34]. They have also a third, clear eyelid that protects their eyes from blowing sand [35].

Large body size and height: The large size and height of the camel can be of some advantage in heat regulation. A large body mass heats up much more slowly than a smaller mass exposed to the sun [36]. Large-bodied animals gain heat from the environment at a slower rate than do smaller animals because they have a lower surface-area-tovolume ratio and higher thermal inertia. The comparatively small surface-area-to-volume ratio of large animals reduces the proportion of the animal exposed to solar radiation, reducing potential environmental heat load. Body size is related to metabolic rate. While their overall energy requirements are higher, large animals have lower 
mass-specific metabolic rates than do small animals; these low metabolic rates contribute comparatively less metabolic heat to the total thermal load [13].

The long legs and the large humps, containing adipose tissue, give camels a large skin surface in relation to the body mass. The height above the ground is used to hold their body far from the hot sand and allows the desert winds free access to the body thus in some circumstances cooling it effectively [15]. It also enables the camels to browse high above the ground reaching 3.5 meters into the canopies of trees and bushes. This characteristic together with their preference to browse on many kinds of bushes makes them an excellent complement for multi-species herds in different kinds of range lands, increasing the productivity of the land without really competing with other livestock [36].

Large foot pads: Their large broad 'elastic' pads with two finger naillike toe nails on front are also important structures to easily walk on the desert sand which is not possible for other ungulates to walk on tips of hoof covered toes. The advantage of this broad leathery pad in camels is to disperse their weight in a wider surface area and their feet don't sink in the loose sandy soil [22].

\section{Behavioral adaptations of camels}

Behaviors of desert camels that aid thermoregulation and the maintenance of water balance include timing of activity, diet selection, use of microhabitats, social behaviors, body orientation, migration, and timing of reproduction [13].

Feeding and drinking behavior of camels: The camel selects only a few leaves from each plant and ingests the foliage parts. It prefers halophytes plants. It can take in a very large amount of water at one occasion for compensating previous fluid loss and it can move for a long distance in the desert to seek water [5].

Camels are very versatile and opportunistic feeders, they accept a wide range of browse species that are often avoided by other species, but also some grasses. Foraging camels normally spread over a large area thus minimizing pressure on a particular area [37].

The camel has preference for feeding at night, in the early morning or late evening or when the sky is clouded or just before and just after sunset. At very hot times camels tend to avoid feeding around midday. Under restricted herding conditions where camels are confined at night, behavior cannot be described as natural since nutritional requirements have to be met in a shortened period and rumination and rest take place for the most part during the hours of darkness. If the camel is allowed to feed at night, it settles on the ground early in the morning before the sun has warmed the ground, thus reducing heat absorption by conduction from the earth to its body [38].

Thermal behavior of camels: The camel avoids sitting in the sun if possible, otherwise faces the sun and does not expose all the body. In the recumbent position, the camel raises its sternum to ensure a "plate like" shape and this allows air circulation [5]. Standing or sitting, the camel gradually keeps shifting its position throughout the day to keep in line with the sun, thus reducing the area subject to direct radiation. When herded in groups and allowed to rest, camels invariably cluster together if conditions are hot, which again reduces the total area subject to radiation. Sheep also adopt this strategy under hot conditions, but unlike sheep which cluster with their heads central to the unit, camels prefer to orient (as they do as individuals) to the sun and move position as the earth rotates [38].
Sexual behavior: Species that inhabit arid and semiarid areas with unpredictable environmental conditions display more opportunistic breeding patterns, with young born over a more extended time period. The camel's reproduction is characterized by a seasonal activity which is typically timed to ensure that parturition occurs at a favorable time of year to maximize offspring survival $[39,13]$.

\section{Conclusion and Recommendations}

Camels adapted to desert areas are able to survive and reproduce despite extreme temperatures and limited water availability using a variety of physiological, anatomical and behavioral mechanisms to either avoid or tolerate environmental conditions that can result in heat stress and dehydration. Camel production has a number of comparative advantages over other domestic animals within the camel's optimal environmental limits. Apart from a number of adaptation mechanisms for desert survival, camels are environmentally friendly animals. Therefore new and improved methods of camel raising must be initiated that will enable man to utilize the natural ability of the camel to produce milk and meat where other animals cannot produce, or produce only with difficulty.

\section{References}

1. Al-Dahash S, Sassi M (2009) A preliminary study on management, breeding and reproductive performance of Camel in Libya. Iraq J Vet Sci 23: 276-281.

2. Wosene A (1991) Traditional husbandry practices and major health problems of camels in the Ogaden, Ethiopia. Nomadic Peoples 29: 21-30.

3. Gaughan JB (2011) Which physiological adaptation allows camels to tolerate high heat load and what more can we learn? J Camelid Sci 4: 85-88.

4. Eltahir Y, Ali H, Mansour M, Mahgoub O (2010) Serum mineral contents of the Omani racing Arabian Camels (Camelus dromedaries). J Anim Vet Adv 9: 764-770.

5. Ouajd O, Kamel B (2009) Physiological particularities of Dromedary (Camelus dromedarius) and experimental implications. Scand J Lab Anim Sci 36: 19-29.

6. Kadim IT, Mahgoub O, Al-Kindi A, Al-Marzooqi W, Al-Saqri NM (2006) Effects of transportation at high ambient temperatures on physiological responses, carcass and meat quality characteristics of three breeds of Omani goats. Meat Sci 73: 626-634.

7. Ali A, Al-Sobayil F, Tharwat M, Al-Hawas A, Ahmed A (2004) Causes of infertility yin female Camels (Camelus dromedarius) in middle of Saudi Arabia. J Agri Vet Med 2: 59-69.

8. Yosef T, Kefelegn K, Mohammed YK, Mengistu U, Solomon A, et al. (2014) Morphological diversities and eco-geographical structuring of Ethiopian camel (Camelus dromedarius) populations. Emir J Food Agri 26: 371-389.

9. McNab BK (2002) The physiological ecology of vertebrates. Comstock, Cornell University, Ithaca, New York, USA.

10. Ramet JP (2001) The technology of making cheese in Butana and Northern Sudan. Nomadic from camel milk (Camelus dromedaries). FAO. People 31: 64-84. Animal Production and Health, Paper, Pp 113.

11. Kataria N, Kataria AK, Agarwal VK, Garg SL, Sahani MS (2001B) Filtered and excreted loads of urea in different climatic conditions and hydration states in dromedary camel. J Camel Pract Res 8: 203-207.

12. Breulmann M, Boer B, Wernery U, Wernery R, El-Shaer H, et al. (2007) A proposal towards combating desertification via establishment of camel farms based on fodder production from indigenous plants and halophytes. UNESCO-Doha, UAE, pp: 14.

13. Cain JW, Krusman NPR, Turner JC (2006) Mechanisms of Thermoregulation and Water Balance in Desert Ungulates. Wild life Soc Bull 34: 570-581. 
Citation: Gebreyohanes GM, Assen MA (2017) Adaptation Mechanisms of Camels (Camelus dromedarius) for Desert Environment: A Review. J Vet Sci Technol 8: 486. doi:10.4172/2157-7579.1000486

Page 5 of 5

14. Salehi E, Morovati MS (2012) Kidney Morphogenesis during Prenatal Development in Camelus dromedarius Embryoes. J Anim Vet Adv 1: 822-882.

15. Kataria N, Kataria AK, Agarwal VK, Garg SL, Shana MS (2001a) Changes in glomerular filtration rate and effective renal plasma flow during seasonal water restriction in Indian camel (Camelus dromedarius). J Camel Pract Res 8: 215-220.

16. Campbell NA, Reece JB, Mitchell LG (1999) Biology. 5th edn. Menlo Park, CA: Benjamin/Cummings.

17. Aleme A, Negassie A (2014) Physiological adaptation of animals to the change of environment: A Review. J Biol Agric Health 5: 2205-2209.

18. Franklin WL (2011) Family Camelidae. In: Wilson DE, Mitterme RA (eds) Handbook of Mammals of the World Vol. 2. Hoofed Mammals. Lynx Edicions, Barcelona, pp: 206-246.

19. Irwin R (2010) Camel. Rektion Books Ltd., London, UK.

20. Willmer P, Ston G, Johnston I (2006) Environmental Physiology of Animals 2nd edn. Blackwell Publishing, Malden MA, USA.

21. Warda M, Zeisig R (2000) Phospholipid- and fatty acid-composition in the erythrocyte membrane of the one-humped camel (Camelus dromedarius) and its influence on vesicle properties prepared from these lipids. Dtsch Tierarztl Wochenschr 107: 368-373.

22. Simenew KW (2014) Characterization of Camelus dromedarius in Ethiopia: Production system, reproduction performances and infertility, Pp: 9.

23. Gaughan JB, Bonner S, Loxton I, Mader TL, Lisle A, et al. (2010) Effect of shade on body temperature and performance of feedlot steers. J Anim Sci 88: 4056-4067.

24. Grigg G, Beard L, Dorges B, Heucke J, Coventry J, et al. (2009) Strategic (adaptive) hypothermia in bull dromedary camels during rut; could it increase reproductive success?. Biol Lett 5: 853-856.

25. Ana Maria V (2011) Transcript of Homeostasis on Camels and Plumeria Homeostasis on Camels and Soap tree Yuccas.

26. Dereje M, Ud'en P (2005) The browsing dromedary camel. Behaviour plant preference and quality of forage selected. Anim Feed Sci Technol 121: 297-308.

27. Badryyah A, Al-Suwaigh R, Al Suhaim A (2005) Comparative study on some biochemical constituents of plasma in male camels and goats. J Camel Pract Res 12: 141-143.
28. Souilem O, Djegham M (1994) La digestion gastriquechez le dromadaire (Camelus dromedarius). Rec Méd Vét 172: 199-208.

29. Gallacher DJ, Hill JP (2006) Effects of camel grazingon the ecology of small perennial plants in the Dubai (UAE) inland desert. J Arid Environ 66: 738-750.

30. Gauthier-Pilters H, Dagg A (1981) Physiology of the Camel. In: TextBook of The Camel, its Evaluation, Ecology, Behaviour and Relationship to man. The Univ. of Chicago Press, Chicago, New York, Canada.

31. Wilson R (1984) The Camel. Longman Publ Co., London and New York.

32. Butler AB, William H (2005) Comparative vertebrate Neuro anatomy: Evolution and adaptation. Jhon Wiley and sons, pp: 215.

33. Simenew K, Mekuriaw M, Tesfaye ST, Fekadu R, Wesinew A, et al. (2013) Reproductive performance of Camelus dromedarius kept under Afar pastoral management system using progeny history testing. J Camelid Sci 6: 100-115.

34. Soliman MK (2015) Functional Anatomical Adaptations of Dromedary (Camelus dromedarius) and Ecological Evolutionary Impacts in KSA. International Conference on Plant, Marine and Environmental Sciences, Kuala Lumpur, Malaysia.

35. Hussein A (2016) Camels and adaptation to water lack: Mirror of Research in Veterinary Sciences and Animals (MRVSA) 5 (1st) on camel diseases and Management 2016, 64-69.

36. Bornstein S (1990) The ship of the desert: The dromedary camel (Camelus dromedarius), a domesticated animal species well adapted to extreme conditions of aridness and heat. Research Management and Husbandry of Reindeer and other Northern Ungulates 1: 231-236.

37. Melaku T, Getachew A (2012) Camel in Ethiopia. Ethio Vet Associa, 1st edn.

38. Muhammad S (2010) To Hot Arid Environment, Ogaden, Ethiopia. Nomadic People 29: 21-30.

39. Zarrouk A, Souilem O, Beckers JF (2003) Breeding news for female dromedaries (Camelus dromedarius). Revue Elev Med Vét Pays Tropi 56: 95-102. 